\title{
The Thermal Characteristics of a Wet Multi-Disc Clutch with Provision for Lubrication Flow
}

\author{
Biao Ma ${ }^{1,2}$, Liang Yü ${ }^{1}$, Heyan $\mathrm{Li}^{1,2}$, Jikai Liu ${ }^{1}$, Mingyang $\mathrm{Li}^{1}$ and Luqi Shi ${ }^{1}$ \\ ${ }^{1}$ School of Mechanical Engineering, Beijing Institute of Technology \\ Beijing, 100081, P. R. China \\ ${ }^{2}$ Collaborative Innovation Center of Electric Vehicles in Beijing \\ Beijing, 100081, P. R. China \\ mabiao@bit.edu.cn; yuliang0516@126.com; lovheyan@bit.edu.cn; \\ 812361107@qq.com; limy1987@163.com; 95690724@qq.com
}

\begin{abstract}
In order to obtain the temperature variations of the clutch hydraulic system, a thermal resistance network model is developed and the lumped parameter analysis is conducted with the relative speed, applied pressure and lubrication flow taken into account. The predicted temperature rises of the clutch and the oil are compared with experimental data. The effects of these parameters on the temperature rise are investigated. Results demonstrate that the thermal model is evaluated as effective and can predict the temperature variations accurately. High relative speed and high applied pressure contribute to the high temperature of the clutch and the oil. However, the larger the lubrication flow, the slower the temperature rise of the clutch, and the faster the temperature rise of the oil. The cooling effect is absolutely obvious with high clutch temperature, while it is not enhanced conspicuously with the lubrication flow increase. Furthermore, the conclusions are of prime importance in efficiency improvements on the thermal management of the clutch system.
\end{abstract}

Keywords: Wet Clutch, Lubrication Oil, Thermal Resistance Network, Temperature, Flow.

\section{Introduction}

The wet clutch is the single most important component in the transmission system, especially in automatic transmissions (ATs) or dual clutch transmissions (DCTs)[1]. The main functions of the clutch hydraulic system are to generate and maintain adequate hydraulic pressure for the clutch operation, as well as lubricating and cooling the clutch. However, too small lubrication flow will bring about the higher surface temperature and the failure of the wet clutch, while the excessive one will give rise to slow engagement and the transmission efficiency could decline dramatically. Bowen $\mathrm{C}$ $\mathrm{W}$, et al.[2] adhibitted the thermal network in the research field of the thermal equilibrium of the transmission system. Moreover, they established the thermal network of the transmission system and analysed the energy and temperature of this system. Based on the hydraulic system, the cooling model of the electric vehicle was developed [3]. Not only the temperature of the engine and the electric elements, but also the thermal response of the cooling components, can be predicted by this model. Taking into account the influence of the heat dissipation of power steering cooler and the radiation heat from the exhaust system components, a simplified one-dimensional transient system was employed in order to study the temperatures during cyclic operation of the cooling system [4]. The temperature field and the heat transfer coefficient were changed because of the various oil flow and speed during the continuous braking, which can provide the theoretical guidance to choose the optimal oil supply [5]. Chalgren, et al.[6] investigated diverse cooling system flow circuits and their effects on heater performance to improve the engine thermal management and climate control of the SUV. The advanced thermal management model was introduced into the hybrid electric vehicle powertrain systems, including the coolant pump, radiator fans, e-motors, and conventional internal combustion engine [7]. However, little attention has been paid to the thermal management of the wet clutch system. In present paper, further investigation is conducted to fill in the gaps in the clutch thermal management.

Herein, a thermal resistance network model of the clutch hydraulic system is developed, in which the components are simplified as nodes based on the lumped parameter method. The average temperature rise of the wet clutch and the oil are obtained. Besides, the effects of the applied pressure, relative speed and the lubrication flow on the temperature rise during 
the engagement process are explored. The simulation is further compared with the bench test. The model can help choose the proper oil flow supply to limit the temperature to a safe level without losing much power. Meanwhile, the model can make it simple to simulate the average temperature rise of the whole hydraulic system in engineering application and harsh working conditions, which cannot be adequately performed in a bench test.

\section{The Thermal Resistance Network Model}

\subsection{The Hydraulic System of the Wet Clutch}

As shown in Fig.1, the hydraulic system can be divided into the controlling oil line and the lubricating oil line, respectively. At the controlling oil line, the oil from the pump, enters the clutch piston through the four-way directional valve. The engagement and disengagement of the clutch are accomplished by charging and discharging of the directional valve. When the piston pressure is built up, the extra oil flows from the outlet of the piston to the tank directly. At the lubricating oil line, the oil flows from the pressure reducing valve to the driving shaft, and then flows out to lubricate and cool the friction components; simultaneously, considerable friction heat will be absorbed by the oil. The heated oil will pass the radiator to cool off before it enters the tank. In addition, the maximum oil pressure of the hydraulic system is determined by the relief valve which is not greater than $1.5 \mathrm{MPa}$. When the oil pressure is slightly higher than the setting pressure, the relief valve allow the extra oil to escape to the tank.

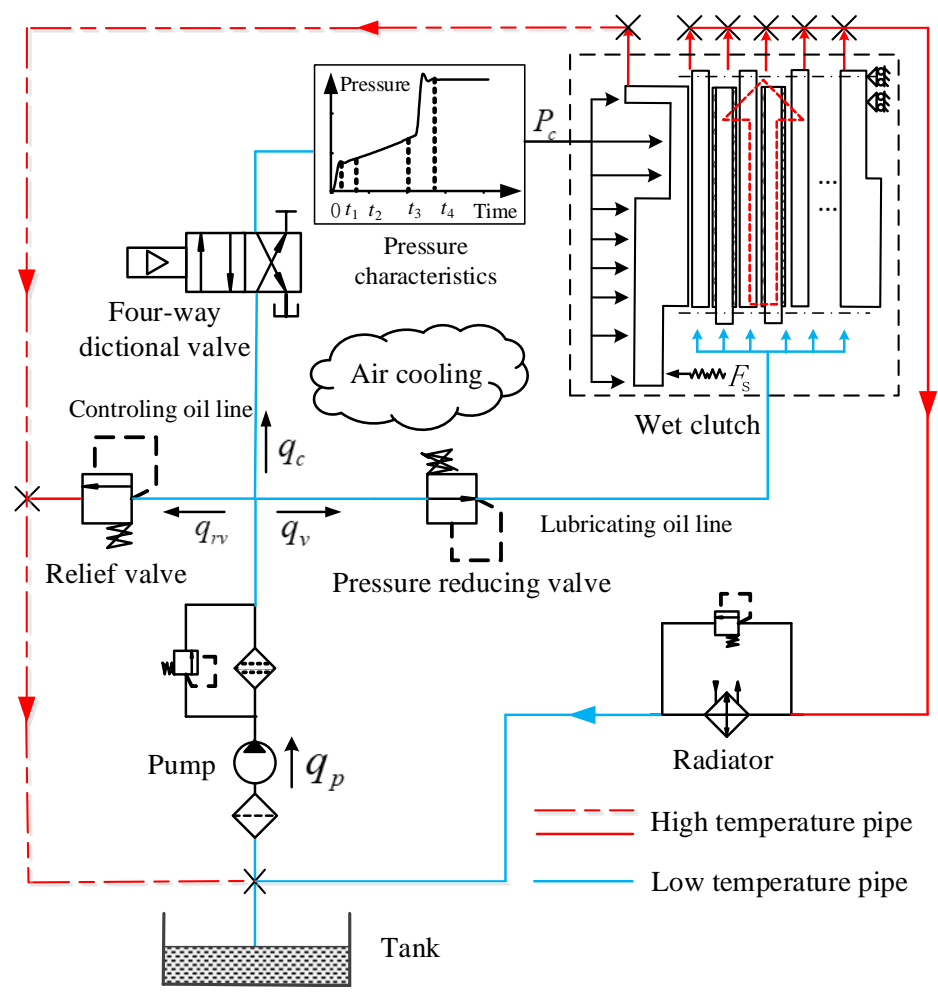

Fig. 1: Hydraulic system of the wet clutch. 
Table 1: Parameters of the hydraulic system.

\begin{tabular}{|c|c|c|}
\hline & Density $\left(\mathrm{kg} \cdot \mathrm{m}^{-3}\right)$ & Specific heat $\left(\mathrm{J} \cdot \mathrm{K}^{-1} \cdot \mathrm{kg}^{-1}\right)$ \\
\hline Steel & $\rho_{\mathrm{g}}=7800$ & $c_{\mathrm{m}}=500$ \\
\hline Oil & $\rho_{\mathrm{o}}=860$ & $c_{\mathrm{o}}=1885$ \\
\hline Air & $\rho_{\mathrm{a}}=1.29$ & $c_{\mathrm{a}}=1.005$ \\
\hline & Mass $(\mathrm{kg})$ & Area $\left(\mathrm{m}^{2}\right)$ \\
\hline Pump & $m_{\mathrm{p}}=8$ & $A_{\mathrm{p}}=0.1$ \\
\hline Relief valve & $m_{\mathrm{rv}}=4$ & $A_{\mathrm{rv}}=0.05$ \\
\hline Pressure reducing valve & $m_{\mathrm{v}}=4$ & $A_{\mathrm{v}}=0.05$ \\
\hline Clutch & $m_{\mathrm{l}}=3.5$ & $A_{\mathrm{c}}=0.05$ \\
\hline & Volume $\left(\mathrm{m}^{3}\right)$ & Area $\left(\mathrm{m}^{2}\right)$ \\
\hline Tank & $V_{\mathrm{o}}=0.1$ & $A_{\mathrm{o}}=0.1$ \\
\hline Oil in tank & $V_{\mathrm{ox}}=0.001$ & $A_{\mathrm{ox}}=0.01$ \\
\hline Air in tank & $V_{\mathrm{ex}}=0.005$ & $A_{\mathrm{ex}}=0.5$ \\
\hline Convective transfer coefficient $\left(\mathrm{W} \cdot \mathrm{m}^{-}\right.$ & $h_{i}=2000$ & $h_{o}=15$ \\
\hline$\left.{ }^{-} \cdot \mathrm{K}^{-1}\right)$ & $d_{1}=25$ & $d_{2}=32$ \\
\hline Pipe diameters(mm) & $r_{i}=86$ & $r_{o}=125$ \\
\hline Friction pairs' radii(mm) & &
\end{tabular}

The flow conservation equation can be written as

$$
q_{\mathrm{p}} \eta_{\mathrm{p}}=q_{\mathrm{c}}+q_{\mathrm{v}}+q_{\mathrm{rv}}
$$

where $q_{\mathrm{p}}$ is the flow of the pump; $q_{\mathrm{c}}$ is the controlled flow; $q_{\mathrm{v}}$ is the flow of pressure reducing valve; $q_{\mathrm{rv}}$ is the flow of relief valve; $\eta_{\mathrm{p}}$ is the volume efficiency of the pump.

The flow of the pressure reducing valve can be determined by the thin-walled hole flow formula.

$$
q_{\mathrm{v}}=B_{1} S_{x} \sqrt{2 \Delta p / \rho}
$$

where $B_{1}$ is the orifice flow coefficient; $S_{x}$ is the orifice area; $\Delta p$ is the differential pressure of the valve's inlet and outlet; $\rho$ is the oil density.

The relief valve is conical and direct-actuated. The flow- pressure characteristics can be expressed as

$$
q_{\mathrm{rv}}=\left\{\begin{array}{lc}
0, & p_{\mathrm{s}}<p_{\mathrm{k}} \\
B_{2} x \pi d \sin \alpha \sqrt{2\left(p_{\mathrm{s}}-p_{\mathrm{k}}\right) / \rho}, & p_{\mathrm{s}} \geq p_{\mathrm{k}}
\end{array}\right.
$$

where $p_{\mathrm{s}}$ is the actual pressure of the oil; $p_{\mathrm{k}}$ is cracking pressure of the relief valve; $B_{2}$ is the orifice flow coefficient; $d$ is the orifice average diameter; $\alpha$ is the half cone angle; $x$ is the opening size;

\subsection{Heat Exchange Analysis in the Wet Clutch}

By simplifying the components and lubrication oil to nodes, the hydraulic system of the wet clutch can be converted to the thermal resistance network model as shown in Fig.2. Moreover, the lumped parameter method is adopted to analysis the thermal behaviour of the whole system, which can only be applied when the following conditions are satisfied: 1. The model just considers the heat exchange between the object and the environment regardless of the heat conduction inside the object; 2 . The temperature gradient in the object is ignored, and assuming the temperature of the whole object is identical; 3. The surface thermal exchange changes the object temperature immediately; 4 . The thermal radiation is negligible, as well as the internal thermal resistance of the object. 


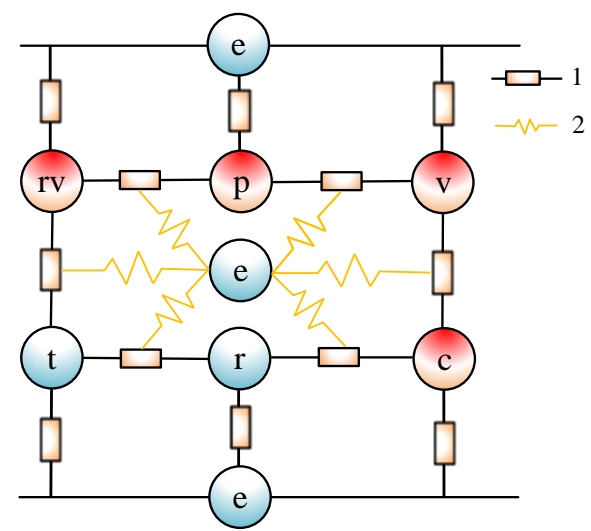

Fig. 2: thermal resistance network of the clutch hydraulic system.

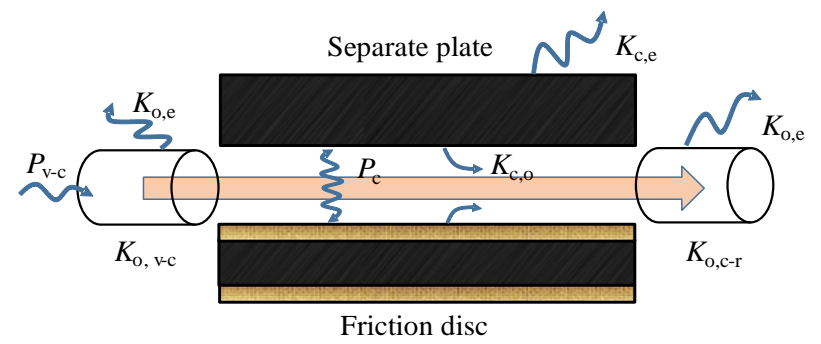

Fig. 3: Heat exchange in the wet clutch.

(e-the environment, rv-relief valve, p-pump, v-pressure reducing valve, c-clutch, r-radiator and t- tank.1-thermal resistance between nodes; 2 - thermal resistance between the pipe and the environment)

Heat-exchange coefficient $K$ is introduced to straightly characterize the heat exchange capacity between nodes. As shown in Fig.3, through the analysis of working process of the wet clutch, it is noted that the production and exchange of clutch heat include: the friction power by virtue of the sliding of friction surfaces $\left(P_{\mathrm{c}}\right)$, the thermal power because of the hydraulic pressure loss in the pipe $\left(P_{\mathrm{v}-\mathrm{c}}\right)$, the heat exchange between the clutch and the oil $\left(K_{\mathrm{c}, \mathrm{o}}\right)$, the heat exchange between the clutch and the environment $\left(K_{\mathrm{c}, \mathrm{e}}\right)$, the heat exchange between the oil and the environment $\left(K_{\mathrm{o}, \mathrm{e}}\right)$, the heat exchange between the oil (from the pressure reducing valve to the clutch) and the environment $\left(K_{\mathrm{o}, \mathrm{v}-\mathrm{c}}\right)$, and the heat exchange between the oil (from the clutch to the radiator) and the environment $\left(K_{\mathrm{o}, \mathrm{c}-\mathrm{r}}\right)$, etc.

The friction power and the thermal power can be written as follows.

$$
P_{c}=\frac{2 \mu z n\left(p_{c} \cdot S_{c}-F_{\mathrm{s}}\right)\left(r_{o}^{3}-r_{i}^{3}\right)}{3\left(r_{o}^{2}-r_{i}^{2}\right)}
$$

where $r_{o}$ and $r_{i}$ are the outer and inner radii of the friction components, respectively; $\mathrm{z}$ is the number of friction surfaces; $n$ is the relative speed; $p_{\mathrm{c}}$ is the applied pressure; $S_{\mathrm{c}}$ is the loaded area of the piston; $F_{\mathrm{s}}$ is the spring force.

$$
P_{\mathrm{v}-\mathrm{c}}=\Delta p_{\mathrm{v}-\mathrm{c}} \cdot q_{\mathrm{v}}
$$

where $\Delta p_{\mathrm{v}-\mathrm{c}}$ is the pressure loss from the pressure reducing valve to the clutch.

$\mu$, the coefficient of friction (COF), can be expressed as follows.

$$
\left.\mu=23 e^{\left(\frac{-2.6 v_{c}}{\left(\ln T_{\mathrm{c}}-3.2\right)\left(\left(28.3 p_{\mathrm{c}}\right)^{0.4}-0.87\right)}-5.16\right.}\right)+\frac{0.01 \ln \left(4 v_{\mathrm{c}}+5\right)}{e^{0.005 T_{\mathrm{c}}}}+0.08\left(e^{-0.005 T_{\mathrm{c}}}-1\right)\left(e^{-0.2 v_{\mathrm{c}}}-1\right)-0.0075 \ln \left(28.3 p_{\mathrm{c}}\right)+0.035
$$


where $v_{\mathrm{c}}$ is the linear velocity of the friction pairs; $T_{\mathrm{c}}$ is the surface temperature of the clutch.

The thermal equations of the clutch node and the oil node can be expressed as

$$
\begin{gathered}
C_{c} \frac{\mathrm{d} T_{c}}{\mathrm{~d} t}=P_{c}-K_{o, \mathrm{c}}\left(T_{c}-T_{\mathrm{o}, \mathrm{c}}\right)-K_{c, \mathrm{e}}\left(T_{c}-T_{\mathrm{e}}\right) \\
C_{\mathrm{o}, \mathrm{c}} \frac{\mathrm{d} T_{\mathrm{o}, \mathrm{c}}}{\mathrm{d} t}=P_{\mathrm{v}-\mathrm{c}}+K_{\mathrm{o}, \mathrm{v}-\mathrm{c}}\left(T_{\mathrm{o}, \mathrm{v}}-T_{\mathrm{o}, \mathrm{c}}\right)-K_{\mathrm{o}, \mathrm{c}-\mathrm{r}}\left(T_{\mathrm{o}, \mathrm{c}}-T_{\mathrm{o}, \mathrm{r}}\right)-K_{\mathrm{o}, \mathrm{c}-\mathrm{e}}\left(T_{\mathrm{o}, \mathrm{c}}-T_{\mathrm{e}}\right)-K_{\mathrm{c}, \mathrm{o}}\left(T_{\mathrm{c}}-T_{\mathrm{o}, \mathrm{c}}\right)
\end{gathered}
$$

where $T_{\mathrm{o}, \mathrm{c}}, T_{\mathrm{o}, \mathrm{v}}$ and $T_{\mathrm{o}, \mathrm{r}}$ are the oil temperatures in the clutch, the pressure reducing valve and the radiator, respectively. $T_{\mathrm{e}}$ is the ambient temperature. $C_{c(0, c)}$ presents the endothermic or exothermic capacity of the clutch (oil) node.

$$
\begin{gathered}
C_{\mathrm{c}(0, \mathrm{c})}=c_{\mathrm{c}(0, \mathrm{c})} \cdot \rho_{\mathrm{c}(0, \mathrm{c})} \cdot V_{\mathrm{c}(0, \mathrm{c})} \\
K_{\mathrm{c}, \mathrm{o}}=K_{\mathrm{o}, \mathrm{c}}=h_{i} \cdot A_{c} \\
K_{\mathrm{c}, \mathrm{e}}=h_{o} \cdot A_{c} \\
K_{\mathrm{o}, \mathrm{v}-\mathrm{c}}=K_{\mathrm{o}, \mathrm{c}-\mathrm{r}}=c_{\mathrm{o}} \cdot \rho_{\mathrm{o}} \cdot q_{\mathrm{rv}} \\
K_{\mathrm{o}, \mathrm{c}-\mathrm{e}}=\left(\frac{1}{h_{i} S_{i}}+\frac{\ln \left(d_{2} / d_{1}\right)}{2 \pi \lambda L}+\frac{1}{h_{o} S_{o}}\right)^{-1}
\end{gathered}
$$

where $c$ is the specific heat; $V$ is the volume; $h_{i}$ and $h_{o}$ are the convective heat transfer coefficient in and out of the pipe; namely, $S_{i}$ and $S_{o}$ are the surface area inside and outside the pipe; $L, d_{1}$ and $d_{2}$ are the length, the inner and outer diameters of the pipe, respectively.

The heat conduction equations of other nodes will not be described due to the fact that heat exchange of those nodes is similar to that of the clutch node. The heat dissipation capacity of the radiator can be determined by the following formula.

$$
Q_{\text {rout }}=\varepsilon(c \rho q)_{\min }\left(T_{1}-T_{2}\right)
$$

where, $\varepsilon$, the heat dissipation performance, can be determined by the coefficient of heat transfer unit [8]; $T_{1}$ and $T_{2}$ are the oil temperatures at the inlet and outlet.

\section{The Simulation of the Average Temperature Rise Characteristics}

In this section, the thermal resistance network model is employed to investigate the average temperature rise of the hydraulic system. Because the specific heat of the oil is much larger than other components, it takes a long time to increase the oil temperature obviously. However, much quantity of friction heat generated in this period gives rise to a sharp rise of the clutch temperature and the temperature has a dramatic influence on COF[9]. Therefore, the simulation is happened in a long time status with low speed and pressure in order to minimize the interference of other variables. The computation parameters of this system listed in table 1, are obtained from the actual physical properties of a heavy-load vehicle. There are three variable parameters in the simulation as shown in Table 2, constituting 18 working conditions. The ambient temperature is kept at $25^{\circ} \mathrm{C}$ and the initial temperature of the clutch is $40^{\circ} \mathrm{C}$. 
Table 2: Working conditions of the multi-disc clutch.

\begin{tabular}{|c|c|}
\hline Parameters & Value(s) \\
\hline Applied pressure (MPa) & $0.1,0.2$ \\
\hline Relative speed (r/min) & $150,300,450$ \\
\hline Lubrication flow (single pair, L/min) & $1,2,3$ \\
\hline Sliding time (s) & 60 \\
\hline
\end{tabular}

\subsection{Analysis of the Average Temperature Rise Characteristics}

Fig.4 demonstrates the average temperature variations of the clutch and the oil flowing out from the clutch. The average temperatures of these two nodes increase over sliding time under different working conditions. The temperature growth rate of the clutch node is slow down gradually; on the contrary, the temperature of the oil node is increasing faster.

Table 3 shows the temperature rise of the clutch node and the oil node at the selected time intervals of 60 s. When the applied pressure and the lubrication flow are constant, the higher the relative speed, the larger the temperature rise of the two nodes. As to the clutch node, there is a direct proportional relationship between the relative speed and the sliding power, and the relationship between temperature and the COF are mutually reinforcing. As a result, when relative speed doubles, the temperature are going up far more steeply than the relative speed had. When the relative speed and the lubrication flow are constant, the greater the applied pressure, the higher the temperature rise of the two nodes. The doubled applied pressure facilitate the sliding surfaces to produce more friction heat. Due to the large temperature difference between the clutch node and the environment, the heat exchange between them is accelerated. The oil node will also draw more heat from the clutch node. Consequently, the clutch temperature increases nonlinearly as the applied pressure rises.

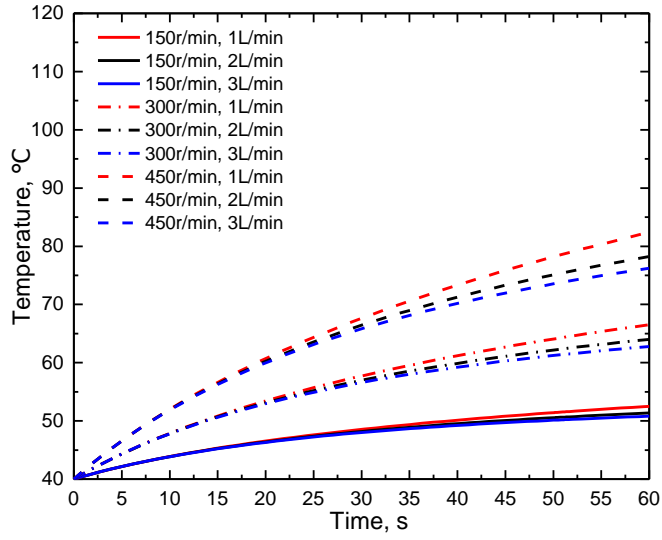

(a) $0.1 \mathrm{MPa}$, clutch

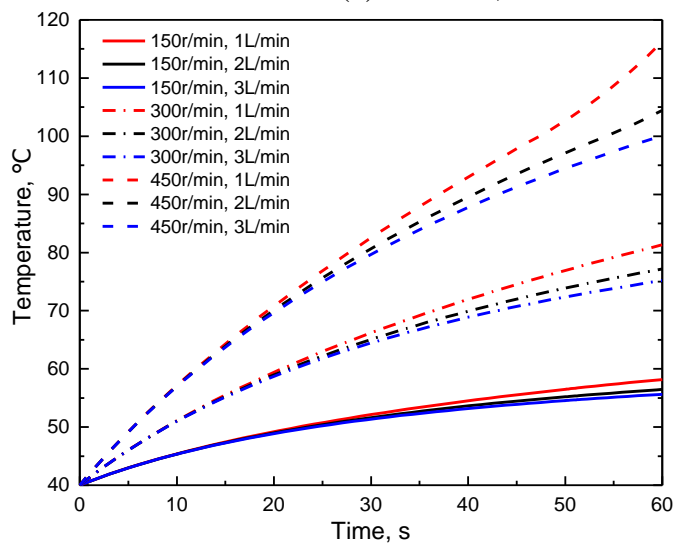

(c) $0.2 \mathrm{MPa}$, clutch

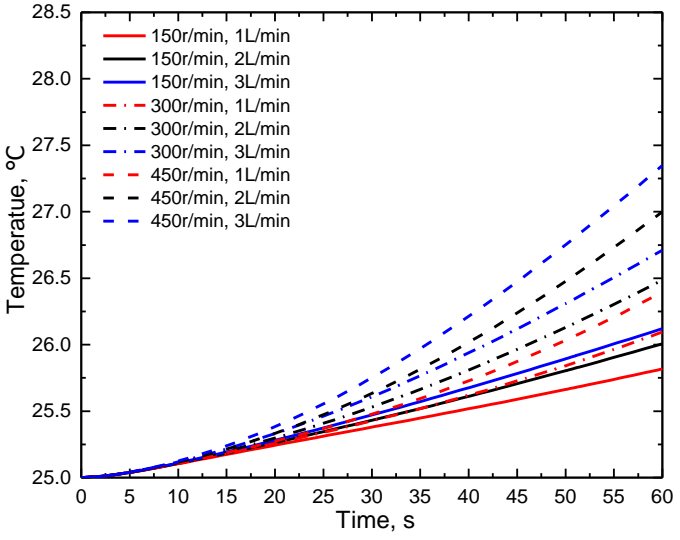

(b) $0.1 \mathrm{MPa}$, oil

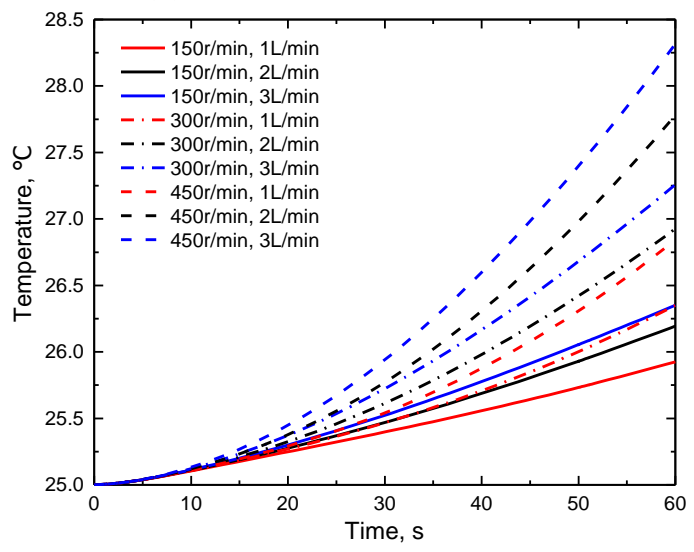

(d) $0.2 \mathrm{MPa}$, oil

Fig. 4: The average temperature variations of the clutch node and the oil node. 
Table 3: The average temperature rises of the clutch node and the oil node $\left({ }^{\circ} \mathrm{C}\right)$.

\begin{tabular}{|c|c|c|c|c|c|c|c|c|c|c|c|c|c|}
\hline \multirow{3}{*}{\multicolumn{2}{|c|}{$\begin{array}{c}\text { Temperature }\left({ }^{\circ} \mathrm{C}\right) \\
\text { Applied pressure }(\mathrm{MPa}) \\
\text { Relative speed }(\mathrm{r} / \mathrm{min})\end{array}$}} & \multicolumn{6}{|c|}{ Clutch node } & \multicolumn{6}{|c|}{ Oil node } \\
\hline & & \multicolumn{3}{|c|}{0.1} & \multicolumn{3}{|c|}{0.2} & \multicolumn{3}{|c|}{0.1} & \multicolumn{3}{|c|}{0.2} \\
\hline & & 150 & 300 & 450 & 150 & 300 & 450 & 150 & 300 & 450 & 150 & 300 & 450 \\
\hline \multirow{3}{*}{$\begin{array}{l}\text { Lubrication flow } \\
\text { (single pair, } \\
\text { L/min) }\end{array}$} & 1 & 12.50 & 26.54 & 42.40 & 18.18 & 41.33 & 76.28 & 0.82 & 1.10 & 1.39 & 0.93 & 1.35 & 1.84 \\
\hline & 2 & 11.36 & 24.01 & 38.24 & 16.46 & 37.19 & 64.47 & 1.01 & 1.49 & 2.00 & 1.19 & 1.93 & 2.78 \\
\hline & 3 & 10.82 & 22.78 & 36.22 & 15.63 & 35.18 & 60.10 & 1.12 & 1.71 & 2.35 & 1.35 & 2.26 & 3.32 \\
\hline
\end{tabular}

When the relative speed and the applied pressure are constant, the higher the lubrication flow, the slower the temperature rise of the clutch node and the faster the temperature rise of the oil node. The reason behind this phenomenon is that the higher the lubrication flow is, the more heat exchange between the oil node and the adjacent oil node takes place in unit time. Therefore, more friction heat of the clutch node is absorbed by the oil node and then enters the hydraulic system, resulting in the lower temperature rise of the clutch node. When the absorbed heat exceeds the heat dissipation of the whole system, the oil temperature will rise with the increase of lubrication flow.

\subsection{Analysis of the Cooling Effect}

In engineering application, the relative speed and the applied pressure of the wet clutch are determined by the practical working conditions which cannot adjust as clutch temperature rises. Thus, the lubrication flow is of great significance to ensure the safe and steady operation of the wet clutch. Table 4 illustrates the temperature variations of both the clutch node and the oil node when the lubrication flow changes from $1 \mathrm{~L} / \mathrm{min}$ to $2 \mathrm{~L} / \mathrm{min}$ and from $2 \mathrm{~L} / \mathrm{min}$ to $3 \mathrm{~L} / \mathrm{min}$ at selected time intervals of 60s.

The higher the temperature in the clutch node, the more obvious the cooling effect. To be more accurate, when the lubrication flow is $1 \mathrm{~L} / \mathrm{min}$ and the applied pressure is $0.1 \mathrm{MPa}$, the temperatures at three different speeds are $12.50^{\circ} \mathrm{C}$, $26.54^{\circ} \mathrm{C}$ and $42.40^{\circ} \mathrm{C}$, respectively. When the lubrication flow becomes $2 \mathrm{~L} / \mathrm{min}$, the temperature decreased by $1.14^{\circ} \mathrm{C}$, $2.53^{\circ} \mathrm{C}, 4.16^{\circ} \mathrm{C}$, respectively. Then, increasing the lubrication flow to $3 \mathrm{~L} / \mathrm{min}$, the temperature further reduced by $0.55^{\circ} \mathrm{C}$, $1.23^{\circ} \mathrm{C}$ and $2.03^{\circ} \mathrm{C}$, respectively. Hence, it is effectively proved that when the clutch temperature is high enough, increasing the lubrication flow will have a superior cooling effect.

Table 4: Temperature variations of the clutch node and the oil node under different lubrication flows $\left({ }^{\circ} \mathrm{C}\right)$.

\begin{tabular}{|c|c|c|c|c|c|c|c|c|c|c|c|c|c|}
\hline \multirow{2}{*}{\multicolumn{2}{|c|}{$\begin{array}{c}\text { Temperature }\left({ }^{\circ} \mathrm{C}\right) \\
\text { Applied pressure }(\mathrm{MPa})\end{array}$}} & \multicolumn{6}{|c|}{ Clutch node } & \multicolumn{6}{|c|}{ Oil node } \\
\hline & & \multicolumn{3}{|c|}{0.1} & \multicolumn{3}{|c|}{0.2} & \multicolumn{3}{|c|}{0.1} & \multicolumn{3}{|c|}{0.2} \\
\hline \multicolumn{2}{|c|}{ Relative speed (r/min) } & 150 & 300 & 450 & 150 & 300 & 450 & 150 & 300 & 450 & 150 & 300 & 450 \\
\hline \multirow{3}{*}{$\begin{array}{l}\text { Lubrication flow } \\
\text { (single pair, } \\
\text { L/min) }\end{array}$} & 1 & 12.50 & 26.54 & 42.40 & 18.18 & 41.33 & 76.28 & 0.820 & 1.100 & 1.390 & 0.930 & 1.350 & 1.840 \\
\hline & $1-2$ & 1.14 & 2.53 & 4.16 & 1.72 & 4.14 & 11.81 & 0.19 & 0.39 & 0.61 & 0.27 & 0.58 & 0.93 \\
\hline & $2-3$ & 0.55 & 1.23 & 2.03 & 0.83 & 2.02 & 4.37 & 0.11 & 0.23 & 0.35 & 0.16 & 0.33 & 0.54 \\
\hline
\end{tabular}

As the lubrication flow increases, the cooling effect of the clutch node is not significantly enhanced. To be more specific, the value of the temperature reduction by increasing the flow from $1 \mathrm{~L} / \mathrm{min}$ to $2 \mathrm{~L} / \mathrm{min}$ is about twice as large as that by increasing the flow from $2 \mathrm{~L} / \mathrm{min}$ to $3 \mathrm{~L} / \mathrm{min}$. Likewise, the temperature rise of the oil node by increasing the lubrication flow from $1 \mathrm{~L} / \mathrm{min}$ to $2 \mathrm{~L} / \mathrm{min}$ is much larger than that by increasing the flow from $2 \mathrm{~L} / \mathrm{min}$ to $3 \mathrm{~L} / \mathrm{min}$. It indicates that the multiplication of the lubrication flow will not contribute to the multiplication of the cooling effect. Thus, when the lubrication flow is large enough (reaching the critical value), increasing additional lubrication flow not only brings a slight effect on heat dissipation, but also increases the power loss of the transmission system.

\section{Experiment Details}

To validate the simulation results of the temperature rise of the clutch node and the oil node, the sliding experiments are derived from a comprehensive test bench. As shown in Fig. 5, the test bench is composed of a wet clutch, a $200 \mathrm{~kW}$ emotor, T/n sensors, fly-wheel, brake, measurement and control system and various control valves, etc. The wet clutch 
consists of three separate plates and three friction discs. The lining material of the friction discs is copper-based powder metallurgy, while the material of the friction discs core and the separate plate is $65 \mathrm{Mn}$ steel. The measurement and control system operates the test bench, as well as monitoring the performance parameters, including torque, rotating speed, lubrication flow, pressure and temperature of the clutch and the oil, etc. The driven components, including separate plates, remain stationary through the brake.

The clutch temperature is measured by K-type thermocouples, which can measure the mid-plane temperature of the separate plates. There are two thermometric plates, each of which has four thermometer holes in the circumference direction. The average value of the measurement results is regarded as the desired clutch temperature. The pressure, temperature and flow of the oil node are measured by corresponding sensors. Before the experiments, a run-in cycle test is carried out for numerous times under lower rotating speed until the stabilized friction characteristics is achieved.

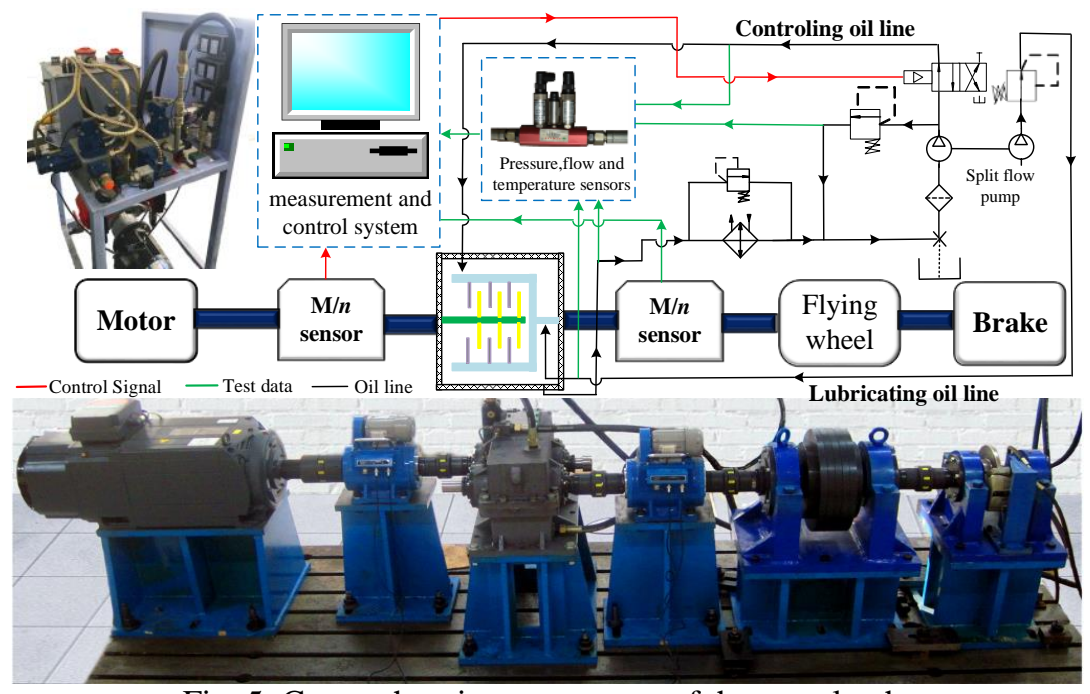

Fig. 5: Comprehensive test system of the wet clutch.

Fig. 6 demonstrates the temperature rise of the clutch node and the oil node under test conditions. It indicates a good agreement between the simulations and experimental results. Therefore, the thermal resistance model of the clutch hydraulic system is efficient and effective in engineering application; simultaneously, the oil flow is approved to be one of the most important approaches to eliminate excessive clutch temperature.

The mean relative errors of the clutch temperature rise are around $2 \%$ 9\% under all working conditions, much larger than these of the oil temperature rise which are almost 1\% 3\%. The reason is that the temperature variations of the clutch node are wider than these of oil node. Due to the fact that there is a large amount of lubrication oil in this hydraulic system, the oil temperature changes are relatively slow, and the difference of the beginning temperature and the finishing temperature is really small, about $3{ }^{\circ} \mathrm{C}$. 


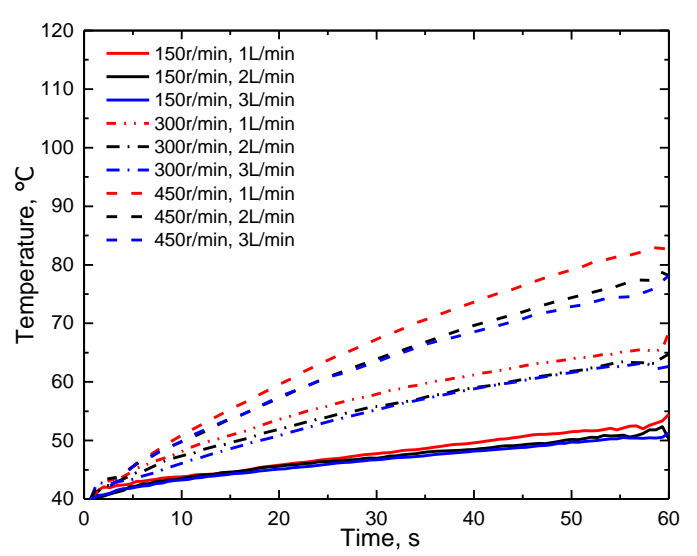

(a) $0.1 \mathrm{MPa}$, clutch

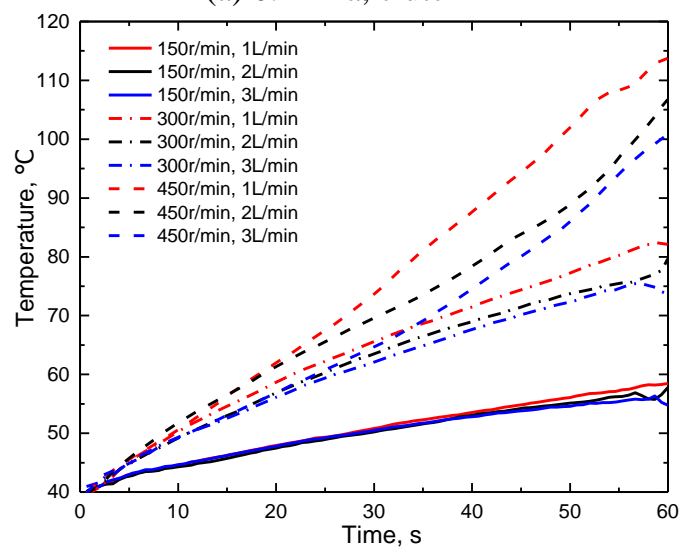

(c) $0.2 \mathrm{MPa}$, clutch

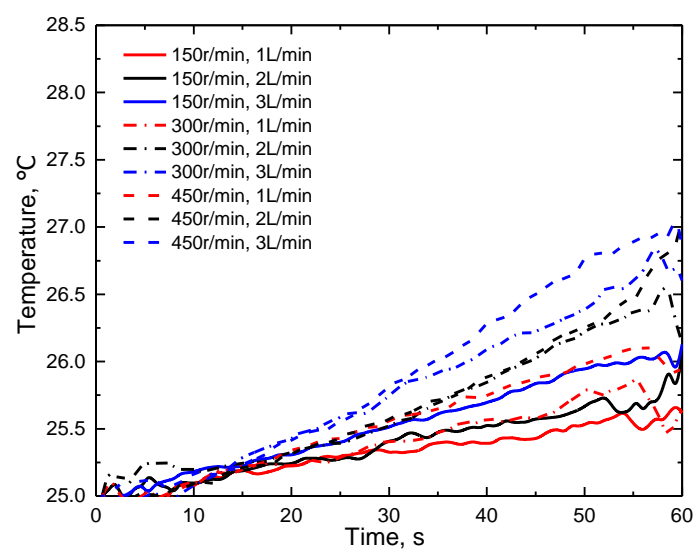

(b) $0.1 \mathrm{MPa}$, oil

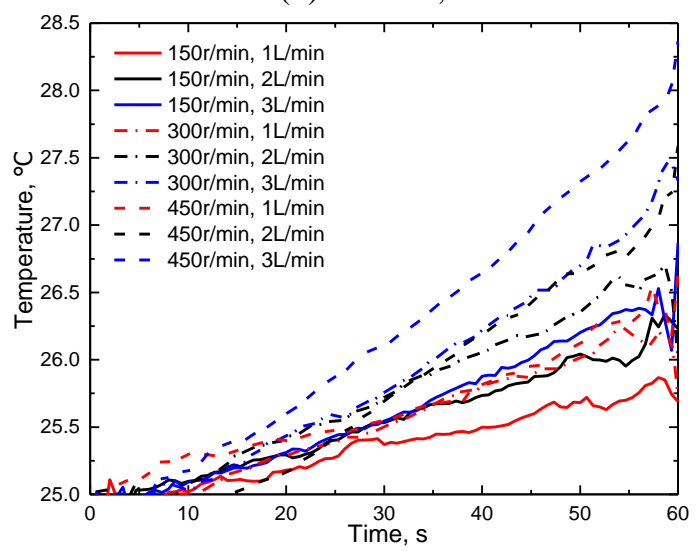

(d) $0.2 \mathrm{MPa}$, oil

Fig. 6: The temperature variations under test condition.

\section{Conclusions}

The thermal resistance network model is developed with the wet clutch, the lubrication oil, the radiator, the pump, various valves and pipes taken into consideration. The lumped parameter analysis is employed to solve the thermal model effectively. It is validated by experimental data and used to explore the temperature rise of the wet clutch and the oil.

The temperatures in clutch node and the oil node are positive correlation with the relative speed and the applied pressure. Nevertheless, the larger the lubrication flow, the slower the temperature rise of the clutch node, and the faster the temperature rise of the oil node. In addition, the cooling effect is absolutely obvious with high clutch temperature. The cooling effect is not enhanced notably with the lubrication flow increase. Therefore, considering the power loss of the transmission system, increasing the lubrication flow unboundedly does not bring substantial benefits. Meanwhile, the conclusions are of great significance in efficiency improvements in the thermal management of the clutch system.

\section{Acknowledgments}

The authors are pleased to acknowledge support from the National Natural Science Foundation of China (Grant NO. 51775045 and NO. 51575042).

\section{References:}

[1] A. P. Ompusunggu, P. Sas, H. Van Brussel, "Modeling and simulation of the engagement dynamics of a wet friction clutch system subjected to degradation: An application to condition monitoring and prognostics," Mechatronics, vol. 23, pp. 700, 2013.

[2] C. W. Bowen, C. E. Braddock, R. D. Walker, "Installation of a High-Reduction-Ratio Transmission in the UH-1 Helicopter," Bell Helicopter Textron Inc Fort Worth TX, 1969. 
[3] S. Park, D. Jung, "Numerical modeling and simulation of the vehicle cooling system for a heavy duty series hybrid electric vehicle," SAE Technical Paper, 2008.

[4] T. C. Scott, J. Uphold, "Thermal modeling of power steering system performance," SAE International Journal of Passenger Cars-Mechanical Systems, vol. 1, p. 1039, 2008.

[5] Y. Wang, B. Wei, "Wet multi-disc friction components heat dissipation capability and optimal oil supply under continuous braking condition," Ind Lubr Tribol, vol. 66, p. 653, 2014.

[6] R. D. Chalgren, "Thermal comfort and engine warm-up optimization of a low-flow advanced thermal management system," SAE Technical Paper, 2004.

[7] X. W. Tao, Design, Modeling and Control of a Thermal Management System for Hybrid Electric Vehicles. 2016.

[8] W. Z. Gao, J. H. Liu, Y. P. Cheng, X. L. Zhang, "Experimental investigation on the heat and mass transfer between air and liquid desiccant in a cross-flow dehumidifier," Renew Energ, vol. 37, pp. 117, 2012.

[9] E. Zhao, B. Ma, H. Li, "Study on the High Temperature Friction and Wear Behaviors of Cu-Based Friction Pairs in Wet Clutches by Pin-on-Disc Tests," Adv Mater Sci Eng, 2017. 